PERSPECTIVA TEOLÓGICA ADERE A UMA LICENÇA CREATIVE COMMONS ATRIBUIÇÃO 4.0 INTERNACIONAL - (CC BY 4.0)

\title{
PENTECOSTALIZAÇÃO ASSENTADA NO ASSENTAMENTO ZUMBI DOS PALMARES, CAMPOS DOS GOYTACAZES, RJ
}

Pentecostalization of the Zumbi dos Palmares Settlement, Campos dos Goytacazes

Fábio Py *

Marcos A. Pedlowski **

RESUMO: $\mathrm{O}$ artigo destaca o crescimento pentecostal vivenciado no assentamento Zumbi dos Palmares, em Campos dos Goytacazes, que fica localizado na região Norte Fluminense. Neste assentamento, em pouco mais de 20 anos de existência, o número de evangélicos pentecostais passou de $7 \%$ a $75 \%$ dos integrantes, modificando a configuração religiosa do assentamento, que apresentava significativa maioria católica nos anos próximos à sua fundação. No artigo, se destaca a mobilidade religiosa, na qual realça a perda de força do catolicismo popular e o crescimento do pentecostalismo no assentamento. No trabalho, se adaptará o conceito de mecanismo de desencaixe, definido por Antony Giddens, para descrever a intensa mobilidade religiosa no assentamento como o processo "desencaixe" dos sujeitos ante determinada dinâmica social e o posterior "reencaixe" em nova conexão social. Para tanto, se utilizará tanto da metodologia quantitativa, quanto de metodologias qualitativas, como entrevistas semiestruturadas e a observação participante.

PALAVRAS-CHAVES: Mudança religiosa. Pentecostalização. Reforma agrária. Assentamento Zumbi dos Palmares.

ABSTRAT: This article highlights the Pentecostal growth occurred at the Zumbi dos Palmares land reform settlement in Campos dos Goytacazes, a municipality located in the North Fluminense region. At this settlement, the number of Pente-

\footnotetext{
* Universidade Estadual do Norte Fluminense Darcy Ribeiro, Campos dos Goytacazes, Rio de Janeiro, Brasil.

** Universidade Estadual do Norte Fluminense Darcy Ribeiro, Campos dos Goytacazes, Rio de Janeiro, Brasil.
} 
costal evangelicals went from $7 \%$ to $75 \%$ of the families over a period of just 20 years, a dramatic change from the mostly Catholic configuration of its original territory. The article highlights the phenomenon of religious mobility as a result of the weakening of popular Catholicism and the growth of Pentecostalism. In the study, the concept of disengagement created by Antony Giddens was adapted to describe the intense religious mobility in the settlement. The study used a qualiquantitative approach to estimate the intensity of the religious disengagement and reengagement process and to gather personal testimonies of key informants to analyze these phenomena.

KEYWORD: Religious Change. Pentecostalization, Land Reform. Zumbi dos Palmares Settlement.

\title{
Introdução
}

\begin{abstract}
A s pesquisas sobre a "mobilidade religiosa" no Brasil vêm afirmando Ao crescimento evangélico no país e a perda de fiéis católicos tanto para as denominações evangélicas quanto para os que se designam sem-religião (LEMOS, 2012; CARRANZA, 2012). ${ }^{1}$ Contudo, são os estudos demográficos de Dias (2017) que se detém mais pontualmente nos números, apontando que o declínio do Catolicismo ocorria na base de $1 \%$ entre as décadas de 1940 até 1980, para, entre os anos de 1991 a 2010, esta queda passar a ser de 1\% ao ano. Sobre eles, é importante de assinalar sobre a contemporaneidade e o processo complexo "de fragmentação do universo religioso brasileiro caindo o peso sobre a decisão subjetiva na escolha e na construção de cada pessoa" (JACOB \& HEES, 2003, p. 88).
\end{abstract}

Sobre isso, Peter Berger (2001) aponta que o indivíduo na sociedade contemporânea tem novas condições para construir uma lógica religiosa, não se relacionando às vestimentas religiosas clássicas. Por outro lado, o trabalho se desconecta ao argumento de Berger sobre as ruralidades quando pondera que "diferentemente do mundo rural, o indivíduo na cidade moderna tem que fazer a sua escolha religiosa, que pode ser a mesma da sua tradição rural - no Brasil o catolicismo agora reinterpretado para o espaço urbano - ou pode fazer outras escolhas religiosas" (BERGER, 2001, p. 29). Em dissonância, o trabalho mostra que certas características do ambiente urbano transbordaram para o ambiente rural do Norte Fluminense, como as tecnologias, mídias e TV (CAMURÇA, 2017). Assim, ao longo do tempo ocorreu um intenso processo de migração de católicos no Assentamento em questão "para adesão consistente pela interpretação protestante e a-

\footnotetext{
${ }^{1}$ Como já apontavam os trabalhos dos anos 2000: Ricardo Mariano (2001), Simone Bohn (2004), Marcelo Camurça (2006), Gedeon Alencar (2007) e Ronaldo Almeida (2008). Da mesma forma, apontaram os trabalhos mais recentes (década de 2010): Marcelo Camurça (2017) e Regina Novaes (2013).
} 
-religiosa da existência" (BERGER, 2001, p. 100). Assim, sobre o declínio do catolicismo no Brasil, Dias (2017) vai mais além, destacando que ele se aprofundou ainda mais entre os anos de 2000 e 2010.

Portanto, Dias (2017) destaca que os maiores responsáveis pela perda da população de católicos são as confissões evangélicas que recebem de $74 \%$ dos ex-católicos tal como Peter Berger (2000) já assinalou em 2000. Em relação a esse processo de migração, Dias aponta que o número de filiações evangélicas tem crescido de forma consistente e em ritmo acelerado, mas que o percentual de crescimento é mais baixo que o crescimento percentual da perda de católicos. Essa diferença se deve ao crescimento dos evangélicos não institucionalizados até pelo grau de fragmentação do universo moderno (JACOB \& HEES, 2003). O demógrafo (DIAS, 2017) sugere ainda que provavelmente no ano de 2022, a quantidade de católicos no Brasil estará abaixo de 50\%, e também, que até o ano de 2040, o número de pessoas que se declaram evangélicos será maior do que os que deverão se apresentar como católicos

Assim, a partir dos dados sobre a "mobilidade religiosa" no Brasil com o consequente crescimento evangélico, o artigo tem como foco analisar o processo de transformação religiosa no maior assentamento de reforma agrária do Norte Fluminense, Zumbi dos Palmares, cuja criação remonta a uma ocupação realizada pelo Movimento dos Trabalhadores Rurais Sem Terra. Nesse sentido, sinaliza-se que o Assentamento Zumbi dos Palmares tem sido palco de uma notável mobilidade religiosa cujo ponto de partida é um catolicismo ligado à Teologia da Libertação, irrigado pelas articulações das ações pastorais (CARVALHÃES \& PY, 2017) - organizadas pela Comissão Pastoral da Terra [CPT] para, na atualidade, uma quantidade de modulações dos pentecostalismos brasileiros.

Portanto, além do trabalho ir ao encontro das pesquisas da demografia (DIAS, 2017), o mesmo visa contribuir para o preenchimento do hiato existente no status quaestionis da sociologia da religião rural no Brasil. Sim, porque os estudos sobre a mobilidade religiosa no meio rural brasileiro são ainda restritos, e, mais ainda, não existem análises compreensivas sobre a presença e impacto das religiões na evolução social e produtiva no interior dos assentamentos de reforma agrária. Assim, o objetivo do artigo não é só destacar o dado da intensa "mobilidade religiosa" (LEMOS, 2012; CARRANZA, 2012), mas os motivos do "desencaixe" religioso na linguagem de Antony Giddens (1991) do catolicismo popular fluminense enfraquecido e o "reencaixe" (principalmente junto) nas adesões pentecostais que se somaram no território a partir de $2000 .^{2}$

\footnotetext{
${ }^{2}$ Danielle Hervieu-Léger (2001) caracteriza esse dado de transmissão religiosa, em sua sociologia da religião a partir das duas figuras: o "peregrino" e o "convertido". A identidade religiosa do "peregrino" se constitui em nome de sua construção bibliográfica subjetiva e da objetividade de uma linhagem religiosa, presente na comunidade em que o individuo se
} 
Assim, a partir da ideia de Peter Berger (2001) da autonomia do indivíduo e da consequente "escolha de adesões religiosas distintas em diferentes temporalidades" (BERGER, 2001, p.101), se chega mais diretamente na teoria social de Giddens (1991)3 , para buscar explicitação dos elementos que ocasionaram a mudança religiosa no Zumbi dos Palmares, onde uma parcela significativa dos seus moradores não mais se encaixa na confissão católica, ou como Giddens (1991) escreve ocorreram uma série de "mecanismos de desencaixes coletivos" (1991), enfraquecendo o monopólio do catolicismo no rural assentado no Norte Fluminense. Junto à teoria do "mecanismo de desencaixe" de Giddens (1991), indicamos essa mobilidade religiosa (LEMOS, 2012) em Zumbi dos Palmares como um conjunto, ou um sistema de "descolagens"/"reencaixes" coletivos, que construíram uma forma de pentecostalismo assentado, possibilitando "novos encaixes, enquadramentos, conexões que se reconectem às transformações técnicas, científicas, religiosas" (GIDDENS, 1991, p. 93).

Com o objetivo de demonstrar essa expansão pentecostal no Zumbi dos Palmares, em Campos dos Goytacazes, o caminho seguido no artigo é iniciado com o histórico da CPT na organização do campo brasileiro, pois o próprio assentamento Zumbi dos Palmares era de maioria católica até pela atividade pastoral da CPT. Assim, a seguir se fará a apresentação do quadro religioso inicial e atual no Zumbi dos Palmares, onde é demonstrada a mudança religiosa ocorrida no assentamento. Ao final deste percurso, serão elencados os motivos que levaram os assentados a se desconectarem da tradição católica para se conectarem com o pentecostalismo, por meio de dezesseis entrevistas e da observação participante realizadas no período de julho de 2017 até outubro de 2018 com moradores do assentamento.

\section{A questão da terra no Brasil e a organização da luta no Rio de Janeiro}

As lutas pela terra e pela reforma agrária no Brasil se intensificaram a partir da segunda metade do século $X X$, quando, em todo o país, os conflitos agrários se aprofundaram, a partir da ação organizada pelos movimentos sociais rurais. A formação de um conjunto de movimentos

\footnotetext{
reconhece. Agora, a figura do "convertido" tem encontro com o fio condutor em três partes: "do individuo que muda de religião, daquele que abraça voluntariamente uma religião e daquele que redescobre sua religião de origem" (HERVIEU-LÉGER, 2008, p. 78). O cabedal teórico da socióloga francesa é parte da pesquisa, contudo, dialogamos mais com a teoria de Antony Giddens para o caso da "mobilidade religiosa" de forma mais direta.

${ }^{3}$ Lemos (2012) sugere que a mobilidade religiosa seria um dos elementos mais comuns na modernidade sugerindo para isso a importância da teoria de Giddens (1991) sobre as transformações culturais, bem como também, Hervieu-Léger (2001; 2008).
} 
sociais do campo ocorreu influenciada pelo processo de industrialização rural. Este processo pode ser relacionado ao ajustamento da economia brasileira à política de substituição das importações, que vinha ocorrendo desde a República Velha e que se aprofundou no período pós-1930 (PY \& PEDLOWSKI, 2018), algo descrito na tabela abaixo.

Tabela 1. Indicadores de modificações estruturais da economia brasileira

\begin{tabular}{|c|c|c|c|}
\hline \multicolumn{4}{|c|}{ Estrutura do Produto Físico (a preços correntes) $(\%)$} \\
\hline & 1907 & 1919 & 1939 \\
\hline Agricultura & 79 & 79 & 57 \\
\hline Indústria & 21 & 21 & 43 \\
\hline \multicolumn{4}{|c|}{ Taxas Anuais de Crescimento (\%) } \\
\hline & Agricultura & Indústria & Total \\
\hline 1920-1929 & 4,1 & 2,8 & 3,9 \\
\hline 1933-1939 & 1,7 & 11,2 & 4,9 \\
\hline 1939-1945 & 1,7 & 5,4 & 3,2 \\
\hline
\end{tabular}

(PY \& PEDLOWSKI, 2018)

A partir da análise dos dados, é possível verificar o valor que a industrialização adquiriu no século $X X$, principalmente durante a Era Vargas (1930-1945). A consequente falta de incentivos estatais aos camponeses agravou as péssimas condições de vida que ocorriam no campo no Brasil. Assim, a partir dos anos de 1950 e 1960, a ação econômica sobre o meio rural organizou-se gerando o desenvolvimento econômico baseado nos seguintes elementos: 1) liberação de mão-de-obra a ser utilizada no setor industrial; 2) mecanização das lavouras, aumentando a quantidade de alimentos; 3) criação de mercado para os produtos da indústria e 4) expansão das exportações. Como consequência de tais ações, destaca-se a ampliação da desigualdade na estrutura rural brasileira (PY \& PEDLOWSKI, 2018; FERNANDES, 2000).

O estado do Rio de Janeiro sofreu diretamente com as políticas nacionais de substituição das importações e da mecanização das lavouras. Em consequência, as lutas sociais agrárias no estado se desenrolaram em consonância com as brasileiras (PY, 2016). Os conflitos rurais fluminenses são o foco das pesquisas de Alentejano (2013), quando aponta que inicialmente as cidades ao redor do município do Rio de Janeiro entraram em processo de urbanização ou de especulação imobiliária. Nesse processo, ocorreu 
"atuação dos grandes empresários de terras e grileiros se optou pela erradicação dos laranjais, dos lavradores, substituindo as áreas agrícolas pelos loteamentos urbanos, ou por gados" (2011, p. 118). Para Alentejano (2013) o crescimento populacional nos municípios de Duque de Caxias, São João de Meriti, Nova Iguaçu e Nilópolis entre 1950 a 1960 foi de 340\%, enquanto no município do Rio de Janeiro esta variação ficou em $80 \%$. Também entre as décadas de 1950 e 1960, o estado investiu na criação de indústrias na região, como a fábrica de motores e a refinaria Duque de Caxias, transformado de área agrícola em espaço especulativo de confluência rural-urbano (ALENTEJANO, 2011; 2002).

Com a expulsão dos trabalhadores rurais entre 1950 e 1960, a atuação do Partido Comunista Brasileiro (PCB) ajudou a organizar o processo de resistência camponesa, incluindo o combate aos despejos, a mobilização de manifestações nas cidades, a realização de apelos às autoridades e, principalmente, de denúncias em jornais. conjuntamente com as ações jurídicas em prol dos agricultores (ALENTEJANO, 2011). Também houve ações armadas de agricultores contra os grileiros, e na década de 1960, com a participação da Federação das Associações de Lavradores do Rio de Janeiro (FALERJ), organizada e impulsionada pelo PCB. Com isso, os conflitos se intensificaram e resultaram no processo de desapropriação de terras em litígio pelo governo Roberto Silveira (1959-1961 - ALENTEJANO, 2011).

Entre as décadas de 1960 e a metade da década de 1980, durante o período da Ditadura Civil Militar, não houve um programa de Reforma Agrária popular, porque a Reforma Agrária foi levada pelos empresários ligados aos setores governamentais brasileiros, como escreve Pedlowski (2011). Assim, na década de 1970, segundo Alentejano (2011) os maiores conflitos rurais ocorridos no território fluminense aconteceram na região da Bacia da Ilha Grande e nas baixadas litorâneas, por conta da construção da rodovia Rio-Santos cortando os municípios de Parati, Angra dos Reis, "facilitando a instalação de grandes projetos industriais junto com a ratificação de fazendas escravagistas"4 $^{\prime \prime}$ (ALENTEJANO, 2002, p. 112).

Na década de 1980, a luta pela terra voltou à Baixada Fluminense, e, diferente das décadas anteriores, quando a disputa era entre grileiros e posseiros, "o conflito se concentra entre a população de desempregados dos bairros pobres das periferias, das favelas que sem alternativas de moradias partem para uma série de ocupações" (ALENTEJANO, 2002, p. 114). Contudo, na década de 1990, já não era mais a Baixada Fluminense o principal foco de conflitos por terras, mas, o norte de Estado. Em 1997 se iniciou o processo de luta pela terra em Campos dos Goytacazes, mais especificamente no complexo de terras da Usina São João, cuja planta industrial se localizava a $7 \mathrm{~km}$ do centro da cidade. A partir desta primeira ocupação, ocorreram outras

\footnotetext{
${ }^{4}$ Mesmo décadas após a abolição da escravatura no Brasil, certos latifúndios mantem trabalhadores rurais em situação análoga à escravidão (STÉDILE, 2006).
} 
27 no Norte Fluminense, sendo 21 delas promovidas pelo Movimento dos Trabalhadores Sem-Terra (MST) - (PY \& PEDLOWSKI, 2018). Destas 21 ocupações, 18 foram em Campos dos Goytacazes (ALENTEJANO, 2002). Um dado que não pode ser esquecido é que em 1985, o município foi palco de uma ocupação ocorrida nas terras da Usina de Novo Horizonte, quando trabalhadores que estavam sem salários devido à falência da empresa ocuparam as terras onde trabalhavam, sob liderança do Sindicato dos Trabalhadores Rurais de Campos dos Goytacazes. A partir deste confronto é que foi acordada a desapropriação das terras de uma fazenda pertencente aos proprietários da Usina Novo Horizonte, beneficiando um total de 101 famílias (ALENTEJANO, 2011).

Na década seguinte, Campos dos Goytacazes, município indicado por Feydt (1979) e Nunes (2003) como tendo uma enraizada e colonial oligarquia canavieira, passou por um amplo processo de falência do seu setor sucroalcooleiro. É importante notar que o processo de falência das usinas de açúcar e álcool ocorreu por conta dos cortes dos subsídios do governo federal para produção de cana e álcool causando problemas nos pagamentos dos salários dos trabalhadores nas safras de 1995 e 1996 (DEW, 2011). Dezenas de usinas de açúcar e álcool foram desativadas, desempregando uma grande quantidade de trabalhadores rurais. Alentejano (2011) e Pedlowski (2011) apontam que essa massa de trabalhadores se tornou o foco das atividades da chamada "Frente de Massas" do MST, que, à época, iniciava o trabalho de base em Campos dos Goytacazes o que resultou na ocupação do complexo de fazendas da Usina São João, sendo esse latifúndio posteriormente chamado de "Zumbi dos Palmares" após o processo de imissão de posse pelo governo federal.

No início das negociações entre o MST e o INCRA, as 559 famílias que estavam acampadas receberiam lotes de terras, sendo que dessas, 200 famílias eram compostas por antigos empregados da Usina (DEW, 2011). Além dos próprios trabalhadores da Usina, os militantes do MST "recrutaram moradores das favelas de Campos, Macaé e São Francisco de Itabapoana"

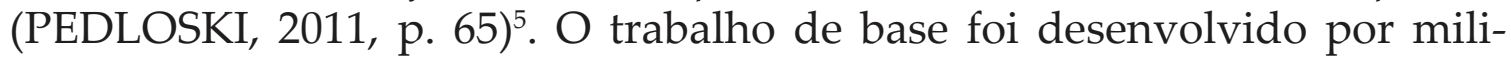
tantes do MST, que foram deslocados dos estados de São Paulo e Paraná que já tinham tido experiência como no Pontal do Paranapanema (PEDLOSKI, 2011). Destaca-se aqui o sucesso do trabalho de base construído pelos militantes ao "estourarem" a ocupação do MST em Campos dos Goytacazes, terra de uma profunda oligarquia da monocultura no estado do Rio. ${ }^{6}$ Após oito meses do início da ocupação, houve o parcelamento de

\footnotetext{
${ }^{5}$ É interessante que se perceba que, com o desenvolvimento do Assentamento de Zumbi dos Palmares, ocorre uma mudança no perfil residencial das famílias do urbano para o rural principalmente nos núcleos: II, III, IV no assentamento (ZINGA, 2004).

${ }^{6}$ Sobre a chamada oligarquia da monocultura de Campos dos Goytacazes e seus vínculos de poder nos Estado do Rio de Janeiro, vide: PEREIRA, 2012.
} 
8500 hectares para 560 famílias, a ideia era transformar o "assentamento no modelo do processo de Reforma Agrária do governo FHC" (PEDLOWSKI, 2011, p. 67). Por isso, o próprio presidente Fernando Henrique Cardoso (FHC) afirmou que nenhuma outra ação de posse da terra tinha sido tão rápida e tão pacifica. Assim, em 12 de outubro de 1997, FHC assinaria o decreto de desapropriação das nove fazendas que compunham o complexo de terras da Usina São João (DEW, 2011).

\section{CPT: formação e fixação no Norte Fluminense}

O sucesso da desapropriação das terras pertencentes à Usina São João é também reflexo do complexo de lutas e dos grupos sociais envolvidos contra o latifúndio no Norte Fluminense (ZINGA, 2004; VIEIRA, 2003). $\mathrm{O}$ envolvimento mais direto do catolicismo se deu diante do cenário de conflitos, miséria e fome que se alastrava no Brasil, nas décadas de 1960 e 1970. À época, principalmente a ala católica ligada à Teologia da Libertação exigia um posicionamento da Igreja (LOWY, 2000). Assim, no ano de 1971, atento aos problemas do campo, o bispo dom Pedro Casaldáliga escreveu uma carta pastoral, na qual denunciava o processo de destruição dos recursos naturais da Amazônia e os crimes cometidos pelos latifundiários contra agricultores e índios. A carta é intitulada de "Uma Igreja da Amazônia em Conflito com o Latifúndio e a Marginalização Social". Esta carta-documento foi o início da reformulação do tratamento das paróquias locais à situação de exploração vivida no Brasil no campo (LOWY, 2000).

A partir da carta repercutida principalmente internacionalmente, surgiram dois braços pastorais da estrutura da Igreja Católica, ambos ligadas à Conferência Nacional dos Bispos do Brasil (CNBB): o Conselho Indigenista Missionário (CIMI), preocupado com o Direito e a diversidade cultural dos povos indígenas e a Comissão Pastoral da Terra (CPT), promovendo um trabalho amplo de pastorais rurais, bem como, registrando os conflitos que envolviam os trabalhadores do campo e a denúncia da violência por eles sofrida (POLETTO, 1985). Ao mesmo tempo, para aumentar o tom à Igreja Católica, por meio da liderança dos bispos Dom Pedro Casaldáliga e de Dom Tomás Balduíno, foi redigida uma série de documentos que apontavam os excessos praticados pelo regime militar (LOWY, 2000).

A criação oficial da CPT se deu no Encontro de Pastoral da Amazônia, organizado pela Conferência Nacional dos Bispos do Brasil (CNBB), realizado em Goiânia, em 22 de junho de 1975 (PY \& PEDLOWSKI, 2018). O surgimento da CPT, em meio a grave situação dos trabalhadores rurais, posseiros e peões, fez com que ela se colocasse, desde sua fundação, contra 
o regime militar, que claramente representava os interesses capitalistas nacionais e transnacionais (STÉDILE \& FERNANDES, 2005; FERNANDES, 2000). A CPT ajudou as paróquias de comunidades rurais por meio da interação com as Comunidades Eclesiais de Base (CEBs), visando romper o isolamento do campo, tendo a preocupação de contribuir na:

articulação das diferentes experiências que construíram novas formas de organização do campesinato. O trabalho da pastoral da Igreja Católica e Luterana foi fundamental para o processo de reorganização dos trabalhadores do campo (...) foi uma das expressões do trabalho ideológico realizado pela Igreja Católica, que teve um papel essencial para o redimensionamento político da luta pela terra em todas as regiões do país, alertando para a necessidade da construção de um movimento nacional. Este trabalho ideológico da CPT foi fruto de um processo de autocrítica vivenciado pela Igreja Católica, principalmente na América Latina (CARVALHAES \& PY, 2017, p. 342).

Como afirmam Stédile e Fernandes (2000), dentre as ações realizadas pela CPT durante o regime militar, merece destaque o apoio dado aos movimentos de luta dos camponeses desapropriados para a construção da hidrelétrica de Itaipu. Além disso, na região oeste do Paraná, junto às CEBs, foram promovidas assessorias, cursos, formação de jovens e camponeses para que os mesmos desenvolvessem a capacidade de analisar a organicidade da realidade social brasileira (LOWY, 2000). Os documentos gerados pela CPT foram "na verdade, as declarações mais radicais jamais publicadas por um grupo de bispos em qualquer parte do mundo" (LOWY, 2000).

Quando se trata de sua estrutura organizacional no Rio de Janeiro, a CPT tem duas equipes de base, uma no Norte Fluminense, em Campos dos Goytacazes, e outra em Nova Iguaçu, na baixada fluminense (NOVICK, 1992). A administração geral e contabilidade são realizadas em Campos dos Goytacazes, e ambas as equipes fazem parte da Regional CPT ES/RJ, com escritório em São Mateus, no norte do Espírito Santo. Inicialmente a CPT se alocou e se fortaleceu no Rio de Janeiro, a partir de 1979 com apoio das paróquias de Nova Friburgo. No Norte Fluminense, a Comissão encontrou pouco apoio pelo caráter conservador da Diocese da cidade de Campos dos Goytacazes (NOVICK, 1992). Todavia, os primeiros agentes da CPT que chegaram em Campos em 1997 tinham a intenção de trabalhar com os assalariados do corte de cana-de-açúcar da região, mas rapidamente passaram a atuar junto aos moradores do assentamento de Novo Horizonte.

A primeira equipe coordenadora da CPT no Norte Fluminense se deslocou da cidade de Cascavel, localizada no oeste do Paraná, vindo, assim, de um contexto diferente do fluminense. A falta de familiaridade dos agentes da CPT com a realidade local resultou em algumas dificuldades junto aos trabalhadores à época. As primeiras atividades da CPT na re- 
gião visavam contribuir para uma aproximação entre os assalariados do corte de cana e os assentados do Novo Horizonte, ambos com $92 \%$ de pessoas diretamente envolvidas com a atividade canavieira. Os primeiros eixos trabalhados pelos agentes da pastoral foram nas áreas de saúde e de educação, quando foram promovidas "oficinas de saúde", difundindo informações acerca das plantas medicinais e das terapias alternativas (PEDLOWSKI, 2011). Também se procurou focar na alfabetização de adultos, conseguindo com ela se aproximar dos cortadores de cana, pois a maioria dos assalariados era analfabeta ou tinha pouquíssima escolaridade (DEW, 2011).

As atividades da CPT não tiveram apoio da hierarquia católica em Campos dos Goytacazes. Ao contrário, os bispos e as lideranças da cúria local escreveram cartas pedindo o seu afastamento do município diretamente para a direção do CNBB. O apoio dado à Pastoral da Terra em Campos foi de alguns religiosos. Como Gonçalves (2012) relata que a CPT em Campos não seria 'igrejeira', ou seja, não tinha vinculação direta com a cúpula diocesana, permitindo relativa independência como foi desde a fixação sem autorização do bispo diocesano. No entanto, por sua autonomia, e por ser considerado um órgão de "fronteira eclesial", a CPT acabou de chegar a locais onde as paróquias não conseguiam se articular, ao mesmo tempo em que, por ser ecumênica, prescinde da afiliação católica como requisito para que alguém possa participar da comissão, limitando, no entanto, sua autonomia eclesial ao bispo diocesano como ocorreu em Campos (GONÇALVES, 2012).

Gonçalves (2012) afirma que a estrutura da CPT em Campos já contou, nos anos 2000, com sete agentes da pastoral fixos e mais três agentes que deram suporte em determinadas atividades. Entretanto, apenas os membros da coordenação da equipe eram remunerados, sendo chamados de "liberados" ("liberados para atividade") se dedicando integralmente à atividade. Destaca-se que os agentes da CPT estão envolvidos, ou já estiveram envolvidos em outros momentos, em iniciativas realizadas em Campos dos Goytacazes, tais como o Movimento pela Educação do Campo, a Escolinha de Agroecologia, de Estudos Bíblicos (ligados à leitura popular da Bíblia), da Comissão Nacional da Erradicação do Trabalho Escravo, do acompanhamento de comunidades quilombolas e do Movimento Fé e Cidadania.

No início do trabalho da CPT no Norte Fluminense, seus agentes participaram da organização do acampamento na Usina São João, que, como já foi dito, posteriormente se tornaria Assentamento Zumbi dos Palmares, atuando em conjunto com o MST. Como escreveu Lewin (2005), no Norte-Fluminense a CPT e o MST "são instituições parceiras", levando a "atingir um público maior e contribuiu, de forma significativa, na formação sociopolítica dos cortadores de cana e outros trabalhadores rurais ou urbanos sem terra do 
Norte Fluminense" (GONÇALVES, 2012, p. 111). No Assentamento Zumbi dos Palmares, a CPT "ajudou principalmente mantendo um ambulatório médico dentro do acampamento e ensinava os acampados a manejarem uma horta com plantas medicinais" (LEWIN, 2005, p. 76).

Embora existam casos de conflitos entre as partes, isto é, entre os agentes da CPT e o corpo do MST, ambos, para Lewin (2005), se caracterizam como sendo "do movimento". Mesmo assim, alguns conflitos envolvendo os assentados e os integrantes da CPT e do MST merecem menção. Para Lewin (2005), os primeiros conflitos teriam ocorrido já no início do Assentamento Zumbi dos Palmares, com a discussão sobre a forma da divisão dos lotes. Contudo, mesmo diante dos conflitos, a CPT teve atuação relevante no Zumbi dos Palmares. Em termos religiosos, a CPT incentivou encontros mensais em missas promovidas pelo padre designado do Distrito de Travessão, que as celebrava na capela situada no centro do Núcleo IV do assentamento. Também ocorreu a construção do coletivo de mulheres Regina Pino (A., 2017), liderado por uma liderança da CPT. Além disso, existem projetos de educação agroecológica levados inicialmente por outra agente pastoral da CPT em 2014 e 2015 (A., 2017; S.. 2017). No ano de 2019, se retornou às atividades da Escolinha Agroecológica envolvendo na primeira metade do ano jovens lideranças de Zumbi dos Palmares, do Quilombo de Cafuringa e também do Assentamento Dandara dos Palmares.

Não se pode deixar de destacar as atividades que ocorrem todo ano no dia 28 de julho, no dia do Agricultor, quando a CPT promove festas com a participação de todo Assentamento e redondezas. Outra atividade importante organizada pela CPT são as chamadas Romarias das Terras, sendo que a XV edição intitulada "No clamor da terra e das águas feridas brotam clamores de justiça", que ocorreu no dia 24 de julho de 2016, contou pela primeira vez com um bispo, Roberto Francisco Ferrería Paz (A., 2018).

Gonçalves (2012, p. 114) observa, porém, que mesmo com as atividades promovidas pela CPT, os próprios agentes da Comissão criticam o "individualismo e a visão mais capitalista da terra de muitos assentados". Para Gonçalves, essa crítica ao suposto individualismo seria um dado da idealização dos agentes pastorais sobre a coletividade de Zumbi dos Palmares. Contudo, não se pode perder de vista que tal preocupação de base comunitária da CPT tem ligação com a própria tradição da Igreja Católica e a tentativa em recuperar o "modelo de vida" (GIDDENS, 1991) das populações rurais, que possuem bases no pensamento social da Igreja católica. Entretanto, na grande maioria dos projetos de assentamentos existentes no Brasil é que cada sujeito assentado preocupa-se basicamente "com a produção no seu lote, e nem muitas vezes, nem sabe muito bem quem é seu vizinho" (GONÇALVES, 2012, p. 115). 


\section{O Assentamento Zumbi dos Palmares e seu quadro religioso}

Após 20 anos de existência, é possível dizer que o Zumbi dos Palmares apresenta atualmente uma diversidade de expressões religiosas e de estruturas religiosas (ALENTEJANO, 2011 - Tabela 2).

Tabela 2. Distribuição de igrejas nos núcleos do assentamento

\begin{tabular}{|ccc|}
\hline Núcleo & Famílias assentadas & Igrejas (2019) \\
\hline I & 150 & 1 \\
II & 79 & 3 \\
III & 63 & 1 \\
VI & 145 & 5 \\
V & 71 & 2 \\
Total: & 506 & 12 \\
\hline
\end{tabular}

Um importante elemento da realidade religiosa encontrada no Zumbi dos Palmares é a diversidade de experiências cristãs, entre as quais se destaca a dos pentecostais. A presença evangélica-pentecostal é maioria hoje em Zumbi dos Palmares, o que já pode ser verificado pela quantidade de igrejas (são 11 no total de 12 igrejas). Um exemplo da presença pentecostal em Zumbi é a trajetória do "irmão Jo" $\mathrm{Jm}^{17}$ trabalhador da construção civil que, incumbido pelo ministério pastoral da Assembleia de Deus - denominação a qual professava -, construiu um templo da denominação no assentamento. Para a construção, feita por ele próprio desde os alicerces, contou com doações das pessoas que frequentavam os cultos, antes, realizados em sua casa (JO., 2018).

Além do exemplo do irmão Jo., um quadro adaptado dos cinco núcleos do Zumbi dos Palmares aponta que a maioria das comunidades religiosas ditas evangélicas que ajudam a povoar o assentamento são igrejas da Assembleia de Deus (AD). Um dado importante é que as igrejas da AD podem ser encontradas em todos os núcleos do assentamento. Por outro lado, mesmo não sendo uma denominação com muitos membros, a Igreja Batista é destacada estando ligada ao "histórico do assentamento", sendo levada por um religioso, o pastor G., bem relacionado com a CPT, como destaca a conversa com o agente da pastoral da terra A. (A., 2017).

No Núcleo I, existe apenas uma comunidade religiosa evangélica, que é da AD. Seus membros se reúnem na casa da senhora Maria Regina. Essa

\footnotetext{
${ }^{7}$ Fez-se opções de nomear as pessoas entrevistadas do Assentamento Zumbi dos Palmares a partir de abreviações.
} 
comunidade tem aproximadamente "20 pessoas que se reúnem aos domingos à noite e às quintas-feiras nas reuniões de oração" (JO., 2018). No Núcleo II, com menos famílias, há uma Assembleia de Deus, uma Igreja Maranata e uma Igreja Universal do Reino de Deus (IURD), sendo que os templos da Maranata e da IURD são mais frequentados, com os cultos dominicais chegando a ter a presença de 50 e 100 pessoas, respectivamente. Um aspecto importante acerca da dinâmica religiosa no Núcleo II é que, embora seja um dos menores em termos de famílias assentadas, apresenta pelo menos três igrejas com relativa frequência, sendo o destaque para a AD do pastor A., que chega a ter uma frequência dominical de 40 pessoas. $^{8}$ No Núcleo III, só existe uma igreja, da $\mathrm{AD}$, com uma frequência de 20 pessoas por celebração de domingo. Já, no núcleo IV, há uma diversidade maior, com dois templos da $\mathrm{AD}$, uma Batista, uma Capela Católica, e uma missão da IURD. A capela católica segue fazendo celebrações mensalmente, com mais ou menos 20 pessoas frequentando.

Em todo território de Zumbi dos Palmares há apenas uma capela católica, que fica localizada no núcleo IV, sendo que os católicos dos demais núcleos frequentam comunidades católicas ao redor, como no Parque Sant'Ana. No início do assentamento havia outra comunidade católica na região no núcleo II, mas a mesma foi abandonada pela falta de missas e pela baixa frequência dos paroquianos. Por fim, no Núcleo $V$, há duas igrejas Assembleia de Deus, uma igreja formada com 40 membros, e a outra, uma congregação da Assembleia de Deus conta no máximo de 10 membros nas principais celebrações. Assim, é interessante observar que o caso do Assentamento Zumbi dos Palmares se relaciona com o quadro religioso brasileiro, colocando a Assembleia de Deus como igreja com maior capilaridade entre as evangélicas, seguido pela Igreja Batista e a IURD. Ao mesmo tempo, chama atenção a forte presença de missões da IURD.

Existe um questionamento por parte dos círculos ecumênicos sobre a relação entre as comunidades religiosas evangélicas e suas relações com as atividades coletivas do Assentamento. Apenas a comunidade batista, que é liderada pelo Pastor G., é vista de forma positiva por ter "identidade de assentado" (A., 2017). Contudo, se diz que é pouco frequentada contando com a presença apenas de "poucos senhores e senhoras que moram ao redor" (P.P., 2017). Outro ponto que merece ser dito é que os próprios membros do Assentamento foram responsáveis pela construção das igrejas, como destacou o irmão Jo., que construiu tanto a Igreja Batista de Campelo, quanto a "Assembleia de Deus: ministério Copacabana", na sua antiga sede.

Assim, o fator da presença dos pentecostalismos é um elemento importante para se pensar o assentamento e sua conjectura hoje. Ao mesmo tempo, esse é um dado que vem sendo desprezado nas análises não apenas no

\footnotetext{
${ }^{8}$ A igreja, sem acesso direto da CPT, tentou no passado uma leiteira, contudo, o empreendimento não obteve êxito.
} 
Assentamento Zumbi dos Palmares como também nos demais assentamentos do Norte Fluminense e do Brasil. ${ }^{9}$

\section{Mobilidade religiosa rumo aos pentecostalismos: análise dos números}

Para se chegar aos dados que apontam a migração de assentados católicos para o pentecostalismo, observaram-se documentos da Junta Catequética dos Padres Redentoristas, que, em 1999, convocou representantes para fazerem desenhos sobre as comunidades que atuavam em Zumbi dos Palmares. Em tais documentos, se verificaram as anotações dos diários pastorais do Padre Tarcísio Generoso da Fonseca (Pe. Fonseca) sobre a afiliação religiosa dos assentados.

Nas anotações do Pe. Fonseca, das 506 famílias, 437 (86\%) se diziam católicas de alguma forma, enquanto que $36(7 \%)$ famílias se diziam evangélicas, 18 (3\%) eram adeptos das matrizes africanas, e 26 (4\%) declaravam não ter religião. Um dado relevante para se entender os desdobramentos futuros em termos de mobilidade religiosa é que, segundo as anotações do Pe. Fonseca, os únicos que não recebiam as orações católicas eram os evangélicos, sendo que os praticantes das religiões de matriz africana pediam orações (DP, 2000). Assumindo tais números dos serviços religiosos, no período de 2000, os católicos eram majoritários, enquanto os que se declaravam evangélicos se portavam de forma claramente apartada dos demais (DP, 2000).

Os dados do Pe. Fonseca serviram como base de comparação com pesquisa encomendada pela Organização Não Governamental Conectas, também ligada à Ordem dos Missionários Redentoristas, que promoveu uma pesquisa acerca das afiliações religiosas dos assentados (CONECTAS, 2018) e concluiu que havia uma maioria expressiva de evangélicos no Zumbi dos Palmares (Tabela 3).

Tabela 3. Religiões no Assentamento em 2017

\begin{tabular}{|ll|}
\hline Religião e/ou igrejas & $\%$ \\
\hline Evangélicos & 72 \\
Católicos & 15 \\
Sem religião & 7 \\
Tradições Afro & 3 \\
Outras expressões religiosas & 2 \\
\hline
\end{tabular}

(CONECTAS, 2018)

\footnotetext{
${ }^{9}$ O que pode ser percebido nos trabalhos sobre a temática: ALENTEJANO, 2011; FARIA,1985; NOVICK,1992; PEDLOWSKI, 2011; POLLETO, 1985.
} 
A comparação dos levantamentos feitos pelo Pe. Fonseca e pela ONG Conectas indica que houve uma mobilidade religiosa vigorosa em quase duas décadas de convivência dentro do Zumbi dos Palmares. Além disso, o fenômeno de migração confessional que ocorre neste assentamento parece ir ao encontro do que ocorreu no interior da população brasileira como um todo que está cada vez mais se tornando evangélica (TEIXEIRA \& MENEZES, 2013; DIAS, 2017). Por outro lado, é possível afirmar que no Zumbi dos Palmares ocorreu crescimento dos que professam confissões de recorte pentecostal acima do gradiente de crescimento dos evangélicos no Brasil. Sobre essa movimentação religiosa (ou mobilidade) que chamamos de pentecostalização assentada.

Uma possível explicação para esse crescimento diferenciado seria a relação entre frequência das celebrações e a distância dos lotes ao local onde as igrejas estão localizadas. O que se ajusta com a sinalização da "falta de sensibilidade do catolicismo institucional aos movimentos sociais, quando os padres e bispos não se comprometem com esses espaços" (JACOB \& HEES, 2003, p. 90). Assim, a relação de maior proximidade pode ter sido um fator que auxiliou no processo de pentecostalização do Zumbi dos Palmares. A frequência e as distâncias são elementos que ajudaram na mobilidade religiosa (LEMOS, 2012), ou no "desencaixe" e o "reencaixe" (GIDDENS, 1991) dos católicos em direção ao pentecostalismo, pois, acarretam uma maior proximidade das instâncias religiosas e aos símbolos da fé. Isto, por sua vez, facilita o acesso aos temas religiosos, bem como a maior circulação dos próprios com os laços da comunidade religiosa. Essa relação foi fortalecida pelo dado de que, a partir de 2000, foram construídas 11 igrejas no Zumbi dos Palmares, todas elas de recorte pentecostal, mesmo a Igreja Batista de Campelo segue práticas pentecostais, tal como J. explicou.

A constatação da passagem marcante do que era uma maioria católica para o pentecostalismo gera uma interessante questão acerca do que teria causado uma transformação tão brusca de pentecostalização assentada, mas também de "descatolização" (BERGER, 2001) - pela falta de interesse direto do clero. Para buscar os elementos causais desta transformação, foram feitas entrevistas entre os anos de 2018 e 2019, com religiosos chaves no cotidiano do Zumbi dos Palmares, que passaram pela mobilidade religiosa, ou como Giddens (1991) "desencaixes" e "reencaixes" religiosos no interior do assentamento. A próxima seção se refere justamente às narrativas oferecidas por assentados que mudaram sua afiliação religiosa após sua chegada ao Zumbi dos Palmares.

\section{Relatos sobre a mobilidade religiosa em Zumbi dos Palmares e a pentecostalização}

Para analisar a mobilidade religiosa como processo de "desencaixes" e "reencaixes" religiosos (GIDDENS, 1991), que se fizeram tão significativos no 
Zumbi dos Palmares, são oferecidas as narrativas de alguns assentados que operaram tal mobilidade religiosa (LEMOS, 2012). Nos relatos que serão apresentados, os assentados apontam os motivos pelos quais deixaram de professar o catolicismo e a aderir às denominações evangélicas.

\section{$5.1 \mathrm{~J} . e \mathrm{I}$.}

O primeiro relato analisado foi oferecido por J., morador do Núcleo II "desde as lonas" (J., 2018). Com 68 anos, J. afirmou que "passou a frequentar a Igreja Assembleia de Deus, porque ela tem programa de TV e Rádio, me sinto mais santo, mais com Deus" (J., 2018). J. recebeu um dos autores do artigo em sua casa em agosto de 2018 e ofereceu seu relato ao lado de sua esposa, que também aderiu à $\mathrm{AD}$. Durante a conversa, o casal informou que fica no lote entre o outono e o inverno, mas que nos períodos mais quentes vão para Bom Jesus de Itabapoana para trabalhar. Durante a entrevista, a esposa (I.) destacou que os programas de TV e rádio da $\mathrm{AD}$ "não bate nas ideias, como em relação aos católicos, que no fim fica mais fácil" (I., 2018). I. explicou que " não bate nas ideias" porque os pastores não usam termos difíceis, que "confundem as ideias como o padre usava catolicismo que tem 'homilias', 'eucaristia', que nunca soube o que significava. Se disseram, não lembro" (I., 2008).

I., que tem 62 anos, e frequenta a igreja da AD do Núcleo I, tem alguma dificuldade de se locomover, relatou que "também era católica, mas não concordava com essas coisas de batina, de santos, daí, com a vinda das igrejas evangélicas e as visitas dos pastores me sinto mais perto, mais próxima. Tenho uma fé mais forte, mais viva". I. seguiu o relato concordando com a cabeça com J. "que se ocorrer qualquer coisa, antes de tudo que o pastor vem cá em casa e ora por mim" (I., 2018). I. confirmou que em caso de qualquer problema o pastor pega a condução e vai a casa deles para conversar, mesmo J. "não sendo mais da igreja", o que implicaria no ato de que tudo "é bem próximo".

O tema da proximidade da modulação evangélica pentecostal é uma condição que Hervier-Léger (2001), em clássico estudo, assume ser de importância das formulações religiosas mais recentes. Esse dado se relaciona diretamente com a oferta de serviço religioso no Zumbi dos Palmares, ou a própria presença nas diferentes mídias pentecostais que se espalham no interior da localidade. $\mathrm{O}$ relato da proximidade na sociabilidade entre as diversas camadas dos religiosos das comunidades pentecostais é certamente um elemento catalizador das mudanças religiosas, ao mesmo tempo, indica a falta de apoio dos líderes religiosos católicos aos movimentos sociais populares (JACOB \& HEES, 2003).

\section{$5.2 \mathrm{Z}$.}

O segundo caso separado de "descolagem" religiosa é o de Z., negra (como se define), com 53 anos, mãe de 4 filhos, e moradora do Núcleo 
II. A entrevista com Z. foi realizada em sua própria casa em setembro de 2018. Ali Z. afirmou que desde os anos 2000 era frequentadora das paróquias católicas da região, mas que passou a frequentar a igreja $\mathrm{AD}$ Central, Ministério Copacabana, na localidade de Campelo, que fica no interior do assentamento, afinal, só tem uma capela católica que celebra uma vez no mês. No período do verão Z. "vai trabalhar nas casas de família na região oceânica, para garantir o sustento do resto do ano do lote" (Z., 2018). Z. tem uma relação um pouco diferenciada de sua aproximação com a expressão pentecostal, pois afirmou que "nos últimos anos sua vida mudou para melhor, não precisa mais esperar a vez do mês para se confessar para o padre que vem ou não para a Capela ou para Travessão. Todos os dias, ela tinha uma coisa para fazer ou na igreja ou nas igrejas do Núcleo II".

Em seu relato, é possível verificar que o descontentamento de Z. com o Catolicismo se deu a partir do pouco acesso ao confessionário, do reduzido acesso à figura do padre, que vinha com baixa frequência ao assentamento (JACOB \& HEES, 2003). Nesse sentido, Z. disse em tom queixoso em direção ao Catolicismo:

"o pastor entende do que ela fala para ele, porque ela tem um namorado, tem filhos e netos. Já o padre, com todo respeito, era um menino de 20, 30 anos que tinha acabado de sair do seminário não entendendo nada do que a vida tem. Não sabe o que é criar filhos, netos, muito menos do que é se deitar todos os dias com a mesma pessoa trabalhando na roça" (Z., 2018).

Então, além da queixa de $Z$. no tocante à baixa frequência dos padres no assentamento, ficou nítida a dificuldade de identificação com o clérigo que visitava o assentamento nas questões da "vida na roça que, por sua juventude, pouco entenderia das dinâmicas familiares" - um relato que realça marcações geracionais diretamente e ressalta a falta de apoio pastoral dos padres na região (BERGER, 2001).

$Z$. ofereceu ainda elementos acerca do descompasso entre os elementos materiais de sua vida no assentamento e a pregação do padre. Segundo Z.:

"a vida na roça e de casa é muito dura para chegar uma vez no mês escutar o padre falar sobre um monte de gente, os padres, histórias, estudos, e não falar nada para mim, nada da vida aqui. Ainda por cima, passar um monte de reza nas confissões. Quero vê, ele aturar esses homens que tive, um deles vivi por mais de 15 anos" (Z., 2018).

A dissintonia em relação a Igreja Católica foi explicitada por Z. a partir da sua discordância com o celibato imposto aos padres, já que o pastor "ao contrário do padre, que não pode se casar, namorar, pelo menos o pastor sabe da "vida de casado, está sempre lá em Campelo, e ainda por cima conhece a vida de trabalho, da roça, dos casamentos. Sabe mais o que se passa nas pessoas, está mais próximo" (Z., 2018). Z. realçou outro elemento ligado às cotidianidades: 
seu pastor vive do trabalho fora do ambiente religioso, logo entendendo a dinâmica dos trabalhadores não eclesiásticos. Ao fazer isto, $\mathrm{Z}$. adicionou ao dado da "desacoplagem" religiosa de Giddens (1991), o elemento geracional, a linguagem e a capilaridade da igreja quando não se atualiza na mesma sintonia que a comunidade a que busca, em tese, servir.

\section{$5.3 \mathrm{~J}$.}

J. foi o terceiro caso analisado de mobilidade religiosa, vista aqui a partir da teoria do "mecanismo de desencaixe" de Giddens (1991). J. foi visitado em outubro de 2018, no quintal de sua casa, no Núcleo IV. J. declarou que era membro da Igreja Batista de Campelo, e disse que "a vida evangélica é melhor porque podem participar com mais facilidade dos cultos do que nas missas. Tem mais acesso a Deus, que falava mais por nós". J. tem 70 anos e comercializa porcos na região, além de ser um pedreiro famoso no Zumbi dos Palmares, pois foi responsável pela construção das primeiras igrejas do assentamento. J. afirmou que construiu as igrejas por ter recebido "de Deus o desígnio de começar as obras, mesmo tendo recebido pouco apoio de todos" (J., 2018).

Em seu relato J. revelou que, em certo momento passou por problemas no meio de uma determinada obra, e por só ele levar o processo, "recebeu de Deus a indicação de que ele era semelhante a Noé, quando todos ao redor não acreditavam na construção, e ainda zombavam e o chamavam de louco" (J., 2018). Segundo J. "acabou de ter vitória, Deus foi maravilhoso com ele", depois de conseguir fazer a igrejinha da $\mathrm{AD}$ e integrar o corpo de fiéis da denominação "cismou de fazer uma igreja do lado de sua casa" (J., 2018). E, assim, construiu a Igreja Batista de Campelo do lado de sua casa, "para facilitar sua ida às celebrações, já que estava envelhecendo". Atualmente J. frequenta a Igreja Batista, mas sua esposa, dona A., prefere ir à AD, dizendo-se fiel às pessoas e às denominações. Segundo A., o esposo "brigou e preferiu sair da igreja e abrir outra" (A., 2018). A. informou ainda que o casal era católico quando foi para o assentamento, mas ainda "nas lonas começaram a se reconhecer evangélicos" (AN., 2018). A razão para a mudança, segundo J. e A. se deveu ao fato de que, entre evangélicos, não haveria necessidade de intermediários para "falar com Deus, uma queixa recorrente na narrativa dos descontentes com o Catolicismo que se tornaram evangélicos.

\section{$5.4 \mathrm{~L}$.}

O quarto caso de mobilidade religiosa é L., pescador e agricultor de 48 anos, que frequenta a igreja da $\mathrm{AD}$ existente no Núcleo $\mathrm{V}$, local, onde participam, no máximo, dez pessoas por celebração no domingo à noite. L. informou que também "sai do lote para trabalhar nas empreitadas ou nos sítios de conhecidos" nos períodos mais quentes do ano (L., 2018). 
L. afirma que passou a ser "crente" há 10 anos, e relatou que já fora católico e se desanimou de religiões. L. afirmou que voltou a se interessar pela vida religiosa por conta dos filhos que tinham amigos que iam para igreja evangélica. Em função dessa influência da rede de amabilidades, L. passou a frequentar a igreja mais próxima do território do assentamento. Além disso, L. admitiu que foram "os filhos que o levaram de volta a Deus, a perceber as coisas de forma diferente, e voltar primeiro a rezar, depois a orar" (L., 2018).

L. lembrou ainda que "era católico e só sabia fazer assim (rezar o sinal da cruz, prece católica), até no dia que foi chamado pelo pastor, por estar fazendo símbolos católicos na igreja", acrescenta que ficou sem graça, mas "achou bom que a oração pessoal era mais intima com Deus" (L., 2018). Segundo L., ele percebeu que a oração evangélica

"não era automática, que poderia falar como se sentisse bem, como se estivesse falando com uns amigos, de pessoas próximas" (L., 2018). L. destacou que vivenciou um despertar religioso "se sentindo parte daquela igreja", pois, além "de ter celebrações semanais, às vezes, por duas ou três vezes na semana" (L., 2018), podia ainda escutar cultos no rádio e na TV, ajudando na sua vida espiritual, se sentindo mais parte da comunidade. A este processo de engajamento vivido por L., Antony Giddens caracteriza como os "novos vínculos emocionais causadores dos desencaixes" (1991, p. 61).

\subsection{PP.}

O quinto caso é o de PP. figura de destaque em Zumbi dos Palmares que publicou um livro de poesias sobre a experiência vivida durante o período do acampamento que resultou na criação do Zumbi dos Palmares. PP. tem 57 anos, além de ser agricultor, tem se ocupado de promover a carreira das filhas como cantoras. PP. foi entrevistado na sala de sua casa ao longo dos meses de janeiro, fevereiro e março de 2018. Em relação à sua afiliação religiosa, PP. indicou que no início do assentamento se dizia católico, mas que hoje prefere se definir como ecumênico e que não frequenta qualquer igreja, tendo assim classificado como "sem-religião". PP. afirma-se ecumênico a partir do vínculo que mantém com a CPT, mas que dialoga com faces pentecostais. Apesar das suas duas filhas frequentarem uma igreja da AD, Ministério Copacabana, PP. indicou que não aderiu à denominação e não se interessa "pelas coisas da igreja porque vê muita coisa errada, porque existem muitas coisas ruins ocorrendo na igreja" (PP., 2018).

PP. parece ser um caso típico de atomização que permitiu a ele não se vincular a uma tradição religiosa, embora tenha "fé em Deus" (PP., 2018). PP. frequentou algumas tradições pentecostais, exercendo o que Hevieu-Léger indica ser um "peregrino de sentido, de sua existência" (2008, p.56- 
91). Tornando um caso diferenciado de "desacoplagem cultural-religiosa" (GIDDENS, 1991), ou seja, a não-religiosa formal, tendo fé, mas não congregando.

\section{Conclusão}

Um primeiro elemento a ser destacado é que as transformações ocorridas na sociedade brasileira das últimas décadas vêm influenciando o rural, ocasionando uma série de mudanças nas vivências, mediante ao acesso às novas técnicas e tecnologias (DIAS, 2017) e se construindo o que Peter Berger chama de "novas sociabilidades religiosas" (BERGER, 2001). Em função disso, é que pode se inferir que uma das consequências é o descolamento de partes significativas da população rural do catolicismo em direção das confissões que são classificadas como pentecostais. Isso porque, como já se indicou o catolicismo contemporâneo (os padres e bispos) "se descola da inteligência dos movimentos (sociais) populares" (JACOB \& HEES, 2003, p.90).

No presente estudo, fica evidenciado que um processo complexo de mobilidade religiosa pode estar ocorrendo também nos assentamentos de reforma agrária, processo este que (quase sempre) pende em direção do Pentecostalismo. Esta hipótese se baseia na existência de uma dinâmica de mudança religiosa complexa do catolicismo ligado à Teologia da Libertação, proeminente na década de 2000, para modulações pentecostais. Tal como se percebeu nas entrevistas arroladas neste artigo, esse catolicismo popular não teve a capacidade de responder às novas dinâmicas da vida dentro do assentamento estudado. Esta incapacidade terminou ocasionando um novo "encaixe" religioso junto às experiências pentecostais. Consideramos que este é um fenômeno de solidificação pentecostal, que o designamos como sendo uma pentecostalização assentada.

Os nossos resultados contribuem para ampliar os resultados de Mafra (2011) que sugeriu que o "cinturão periférico das metrópoles cariocas seriam pentecostais". Pelo que pudemos demonstrar, o processo de pentecostalização dos brasileiros não se resume mais ao cinturão periférico urbano, pois também está presente na área rural do Norte Fluminense. Como abordamos neste trabalho, uma parcela significativa dos assentados de reforma agrária está se mobilizando na direção das experiências pentecostais. Mesmo em um assentamento com área extensa, como é o caso Zumbi dos Palmares, que possui cinco núcleos com características diferenciadas na evolução social e produtiva, notamos a presença deste processo de pentecostalização. Ao menos no caso do Zumbi dos Palmares, não há dúvida que este assentamento passou por uma vertiginosa pentecostalização, ao longo de duas décadas. 
O nosso estudo sugere que este processo de mudança religiosa teria ocorrido mediante a uma rede complexa de "desencaixes" e "reencaixes", nos quais foram se somando (GIDDENS, 1991), confluindo no interior do Assentamento Zumbi dos Palmares uma larga mobilidade religiosa desde o Catolicismo para as igrejas e congregações pentecostais. Isto força o reconhecimento que, em contrapartida, nas áreas rurais do Brasil pode estar ocorrendo uma "descatolização" da fé (BERGER, 2001). Um dos elementos chaves para que isso possa estar ocorrendo tem que a ver com o que foi salientado por Weber (1997) no início do século XX: o Catolicismo apresentaria uma afinidade negativa com a Modernidade, pois se apoia na tradição e nas suas memórias institucionalizadas, sendo assim pouco versado na convulsão das experiências religiosas cotidianas que são as formas mais típicas das diferentes variantes do Pentecostalismo no Brasil. A questão que está reservada para outros estudos tem a ver com a amplitude desse processo nas diferentes regiões brasileiras, de modo a que se verifique se este é um fenômeno pontual ou generalizado.

\section{Referências}

A-Entrevista concedida na praça central do Núcleo IV do Assentamento Zumbi dos Palmares, Campos dos Goytacazes, outubro, 2017.

ALENCAR, G. Protestantismo tupiniquim: hipóteses sobre a (não) contribuição evangélica cultura brasileira. São Paulo: Recriar, 2007.

ALENTEJANO, P. Luta por terra e reforma agrária no Rio de Janeiro. Revista Fluminense de Geografia, Niterói, v. 1, n. 1, p. 109-124, 2002.

ALENTEJANO, P. O Norte Fluminense, a luta pela terra e a política de reforma agrária no estado do Rio de Janeiro. In: PEDLOWSKI, M. A.; OLIVEIRA, J. C.; KURY, K. A. (Orgs.). Desconstruindo o latifúndio: a saga da reforma agrária no Norte Fluminense. Rio de Janeiro: Apicuri, 2011. p. 19-55.

ALMEIDA, R. Os pentecostais serão maioria no Brasil? Rever, São Paulo, n.4, v.3, p.45-67, 2008.

A, Entrevista concedida no quintal de sua casa no Núcleo IV do Assentamento Zumbi dos Palmares, Campos dos Goytacazes, outubro, 2018.

BERGER, P. A Dessecularização do Mundo: uma visão global. Religião e Sociedade, Rio de Janeiro, 21, p. 9-23, 2001.

BOHN, S. R. Evangélicos no Brasil. Perfil socioeconômico afinidades ideológicas e determinantes do comportamento eleitoral. Opinião pública, Campinas, v. 10, n. 2, 2004.

CAMARGO, C. P. Igreja e desenvolvimento. São Paulo: Cebrap, 1997.

CAMURÇA, M. A. A realidade das religiões no Brasil no Censo do IBGE 2000. In: TEIXEIRA, F.; MENEZES, R. (Orgs). As religiões o Brasil continuidades e ruptura. Petrópolis: Vozes, 2006. p.35-46. 
CAMURÇA, M. A. Os "sem religião" no Brasil: juventude, periferia, indiferentismo religioso e trânsito entre as religiões institucionalizadas. Estudos de Religião, São Bernardo do Campo, v. 31, n. 3, p. 55-70, 2017.

CARRANZA, B. Juventude em movimento política-linguagens-religião. In: OLIVEIRA, P.; MORI, G. (Orgs.), Mobilidade religiosa: linguagens, juventude, política, São Paulo: Paulinas, 2012. p. 207-242.

CARVALHAES, C.; PY, F. Liberation Theology in Brazil. CrossCurrents, Chicago, v. 67, p. 157-179, 2017.

CONECTAS. Arquivo religioso sobre pastorais sociais: década de 2010. Rio de Janeiro: Arquidiocese do Rio de Janeiro, 2018.

DEW, E. Samba revolucionário: a revolta agrária que quase todo mundo apoia. In: PEDLOWSKI, M. A.; OLIVEIRA, J. C.; KURY, K. A. (Orgs.). Desconstruindo o latifúndio: a saga da reforma agrária no Norte Fluminense. Rio de Janeiro: Apicuri, 2011. p. 58-98.

DIAS, J. E. Distribuição espacial da transição religiosa no Brasil, Tempo Social, São Paulo, v. 29, n. 2, p. 215-242, 2017.

DP (Diário Paroquial). Arquivo III - seção 1B, Arquivo Diocesano. Campos dos Goytacazes, 2018.

FARIA, S. S. C. Terra e trabalho em Campos dos Goytacazes, 1850-1920. 1985. Dissertação (Mestrado em História Social) - Universidade Federal Fluminense, Rio de Janeiro, 1985.

FERNANDES, B. M. A formação do MST no Brasil. Petrópolis: Vozes, 2000.

FERNANDES, B. M.; STÉDILE, J. P. Brava Gente: a trajetória do MST e a luta pela terra no Brasil. São Paulo: Fundação Perseu Abramo, 2005.

GIDDENS, A. As consequências da modernidade. São Paulo: EdUnesp, 1991.

GONÇALVES, R. L. Atuação da Comissão Pastoral da Terra (CPT) em Campos dos Goytacazes, RJ: Uma análise do Assentamento Zumbi dos Palmares. Dissertação (Mestrado em Extensão Rural) - Universidade Federal de Viçosa, 2012.

HERVIEU-LÉGER, D. A transmissão religiosa na modernidade: elementos para a construção de um objeto de pesquisa. In: CAMPOS, L. (Org). Por uma sociologia do protestantismo brasileira. São Bernardo do Campo: UMESP, 2001. p. 39-54.

I. Entrevista concedida no quintal de sua casa, no Núcleo II do Assentamento Zumbi dos Palmares, Campos dos Goytacazes, agosto, 2018.

J. Entrevista concedida no quintal de sua casa no Núcleo IV do Assentamento Zumbi dos Palmares, Campos dos Goytacazes, outubro, 2018.

JACOB, C. R.; HEES, D. R. (Eds.). Atlas da Filiação Religiosa e Indicadores Sociais no Brasil. Rio de Janeiro/São Paulo, PUC-Rio/Loyola/CNBB, 2003.

JO. Entrevista concedida no quintal de sua casa, no Núcleo III do Assentamento Zumbi dos Palmares, Campos dos Goytacazes, agosto, 2018.

L. Entrevista concedida na Congregação da Assembleia de Deus: ministério Copacabana, no Núcleo V do Assentamento Zumbi dos Palmares, Campos dos Goytacazes, agosto, 2018. 
LEMOS, C. T. Mobilidade religiosa e suas interfaces com a intimidade e a vida cotidiana. In: OLIVEIRA, P. A.; MORI, G. (Orgs.) Mobilidade religiosa: linguagens, juventude, política. São Paulo: Paulinas, 2012. p.119-144.

LEWIN, H. Uma nova abordagem da questão da terra no Brasil: O caso do MST em Campos dos Goitacazes. Rio de Janeiro: FAPERJ/7Letras, 2005.

LOWY, M. A guerra dos deuses: religião e política na América Latina. Petrópolis: Vozes, 2000.

MAFRA, C. O problema da formação do 'cinturão pentecostal' em uma metrópole da América do Sul”, Interseções, Rio de Janeiro, v. 13, n. 1, p. 136-152, 2011.

MARIANO, R. Análise sociológica do crescimento pentecostal no Brasil. 2001. Tese (Doutorado em Sociologia) - Universidade de São Paulo, São Paulo, 2001.

NOVAES, R. Jovens sem religião: sinais de outros tempos. In: TEIXEIRA, F.; MENEZES, R. Religiões em movimento: o Censo de 2010. Vozes: Petrópolis, 2013. p.175-190.

NOVICK, V. A. Governo Brizola, movimentos de ocupação de terras e assentamentos rurais no Rio de Janeiro (1983-1987). In: Assentamentos rurais: uma visão multidisciplinar. São Paulo: Unesp, 1992. p.69-89.

PP. Entrevista concedida na sua sala no Núcleo VI do Assentamento Zumbi dos Palmares, Campos dos Goytacazes, setembro, 2018.

PEDLOWSKI, M. Os limites da reforma agrária dessastida na região norte do Estado do Rio de Janeiro: entre o descaso do Estado e a resistência dos assentados. In: PEDLOWSKI, M. A.; OLIVEIRA, J. C.; KURY, K. A. (Orgs.). Desconstruindo o latifúndio: a saga da reforma agrária no norte fluminense. Rio de Janeiro: Apicuri, 2011. p. 119-136.

PEREIRA, W. Francisco Ferreira Saturnino Braga: negócios e fortuna em Campos dos Goytacazes. História, São Paulo v. 31, n. 2, p. 67-103, 2012.

POLLETO, I. As contradições sociais e a Pastoral da Terra. In: PAIVA, V. (Org.). Igreja e a questão agrária. São Paulo: Loyola, 1985.

PY, F.; PEDLOWSKI, M. A. Atuação de religiosos luteranos nos movimentos sociais rurais do Brasil de 1975 à 1985, Tempo, Niterói, v. 74, n. 2, 2018.

RIBEIRO, M. Movimento camponês, trabalho e educação: liberdade, autonomia, emancipação: princípios/fins da formação humana. São Paulo: Expressão Popular, 2013.

S. Entrevista concedida na praça central do Núcleo IV do Assentamento Zumbi dos Palmares, Campos dos Goytacazes, outubro, 2017.

STÉDILE, J. P. (Org.). A questão agrária brasileira: história e natureza das Ligas Camponesas (1954-1964). São Paulo: Expressão Popular, 2006.

VIEIRA, R. R. M. A influência dos fatores endógenos e exógenos na alocação de recursos financeiros dos beneficiários da Reforma Agrária: um estudo de caso em Campos dos Goytacazes. 2003. Dissertação (Mestrado em Políticas Sociais) - Universidade Estadual do Norte Fluminense Darcy Ribeiro, 2003.

WEBER, M. A ética protestante e o espírito do capitalismo. São Paulo: Pioneira, 1997. 
ZINGA, M. Um estudo de caso sobre as causas da permanência e da resistência no Assentamento Zumbi dos Palmares, Campos dos Goytacazes, RJ. 2013. Dissertação (Mestrado em Políticas Sociais) - Universidade Estadual do Norte Fluminense Darcy Ribeiro, Rio de Janeiro, 2004.

Z. Entrevista concedida na sua cozinha no Núcleo II do Assentamento Zumbi dos Palmares, Campos dos Goytacazes, setembro, 2018.

Artigo submetido em 22.05.2020 e aprovado em 02.12.2020.

Fábio Py é Doutor em Teologia pela Pontifícia Universidade Católica do Rio de janeiro. Pós-doutorado pela Universidade Estadual do Norte Fluminense Darcy Ribeiro. Professor do Programa de Pós-Graduação em Políticas Sociais da Universidade Estadual do Norte Fluminense Darcy Ribeiro. Editor da Revista Agenda Social Contribuição no artigo: abordagem do conteúdo sobre teologia e religiões, citações e referências. Orcid.org/0000-0002-7634-8615. E-mail: pymurta@gmail.com.

Endereço: Rua Sebastião de Lacerda 31 - Apto. 501

Laranjeiras

22240-110 - RJ

Marcos A. Pedlowski é PhD em Environmental Design and Planning pela Virginia Polytechnic Institute and State University. Professor Associado do Laboratório de Estudos do Espaço Antrópico da Universidade Estadual do Norte Fluminense Darcy Ribeiro (UENF). Docente do Programa de Pós-Graduação em Políticas Sociais da UENF. Contribuição no artigo: preparação do desenho experimental, contribuição no processo de análise dos dados obtidos na pesquisa de campo, e elaboração do manuscrito especialmente no que se refere à reforma agrária na região Norte Fluminense. Orcid.org/0000-0003-3949-8240. E-mail: pedlowma@uenf.br

Endereço: Avenida Sete de Setembro, 20

28013-332 Campos dos Goytacazes - RJ 